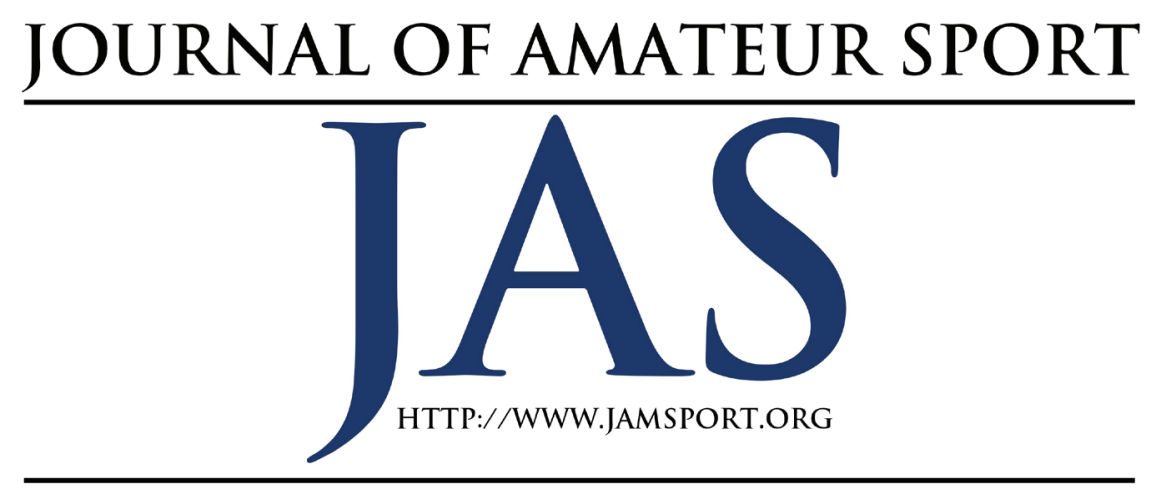

\title{
Collegiate Sport Participation and Student-Athlete Development through the Lens of Emotional Intelligence
}

\author{
Gregory Lott ${ }^{1} \quad$ Brian A. Turner ${ }^{2}$ \\ ${ }^{1}$ Denison University \\ ${ }^{2}$ The Obio State University
}

A continued debate persists over the place of sport within institutions of higher education. Proponents of sport champion its ability to contribute to a holistic notion of education and develop an array of competencies touted in institutional missions. There is however a dearth of empirical data examining the educational impact of athletic participation at the college level. This paper assessed the educational ability of collegiate sport participation in a unique manner, through the lens of Emotional Intelligence (EI). Student-athletes and students at five NCAA Division III institutions completed online assessments prior to and after the completion of the winter sports seasons. Evidence was produced that participation in a single season of collegiate sport does not develop interpersonal, intrapersonal, and leadership capacities significantly differently from the collegiate experience of students not participating in athletics. Institutions are advised to explore EI interventions as way to maximize the educative potential of sport.

Keywords: athletics, intrapersonal development, interpersonal development, liberal arts, division III

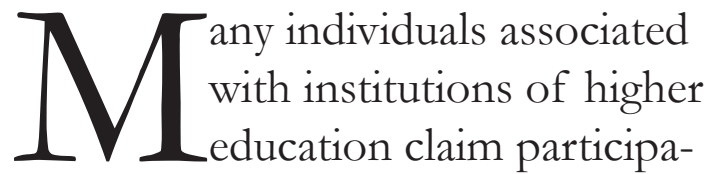

tion in collegiate sport to be an integral curricular component of a holistic education (Aries, McCarthy, Salovey, \&
Banaji, 2004) - developing interpersonal and intrapersonal competencies that better prepare student-athletes for success while enrolled and as postgraduates (Vella, Crowe, \& Oades, 2013). Rhetoric surrounding sport participation has often 
focused on creating leaders through the development of specific capacities such as strategic and tactical thinking, self-awareness, and an improved understanding of interpersonal relationships (Brand, 2006). There exists, however, a lack of empirical evidence to justify such proclamations (R. Feezell, 2015).

There are strong proponents of including sport as an integral educational component of the student experience, yet there are also those that malign its presence, claiming college sport to be in direct contrast with the purpose of higher education. Scholars have addressed this distinct disconnect and genuine friction between academic and athletic units on campuses across the country ( $T$. Feezell, 2015). The focus of such discussions has typically revolved around the high-stakes nature of NCAA Division I athletics (e.g., Stancill, 2014). Yet, some have argued that the strain between faculty and athletics is exacerbated within the framework of NCAA Division III, where many colleges and universities attempt to field a comparable menu of options as Division I institutions, but with proportionally fewer means (Lytle, 2003). Most attempts to quantify the impact of sport on student-athletes have examined metrics such as grade point average, retention rates, and the average starting salaries of graduates (e.g., Shulman \& Bowen, 2001). There then lacks assessment of whether sport develops participant competencies in a manner that specifically pertains to institutional aspirations. There especially lacks such investigation of sport within NCAA Division III where, "claims for the educational value of athletic participation are most clearly and forcefully articulated" (Emerson, Brooks, \& McKenzie, 2009, p. 65).

According to the Fulks (2015), 450 institutions (roughly $40 \%$ of the total NCAA membership) compete in the division with member enrollments ranging from 256 students to over 23,000. NCAA Division III membership consists of both private and public institutions categorized as baccalaureate colleges, master's universities, and doctoral universities (Rasmussen \& Rasmussen, 2003). It therefore becomes quite apparent that while Division III members might share a similar athletic philosophy, such substantial intragroup differences prohibit a homogenous set of core beliefs and institutional missions. If as suggested we are to assess sport participation against the language of institutional missions (R. Feezell, 2015), it becomes imperative to examine a subset of Division III with comparable core objectives.

The researchers identified a particular subset of Division III - residential, liberal arts colleges and universities because of the commonalities between their institutional missions. The vast majority of such institutions compete within Division III (National Liberal Arts College Rankings, 2016). Their mission statements often discuss communication, ethical reasoning, and self-awareness (Knapp, 2013), developing the ability to engage in dialogue with a diverse com- 
munity (Lowry, 2014), or strengthening the aptitude to lead in a rapidly changing and complex world (Durden, 2009). A unifying component of institutional missions within the liberal arts is the purposeful development of intrapersonal awareness and interpersonal skills.

The construct of Emotional Intelligence (EI) encompasses such competencies - touted in the rhetoric surrounding sport participation, and characterized as central to the educational missions of liberal arts institutions. Many have suggested that EI may be important to the context of sport (Meyer \& Fletcher, 2007) yet research has focused almost entirely on correlating EI with sport-performance enhancement, studying the construct to ascertain if an athlete or coach's abilities to effectively manage both their emotions and those of team members can enhance specific outcomes such as overall team wins or improved offensive statistics (e.g., Crombie, Lombard, \& Noakes, 2009; Sough, Clements, Wallish, \& Downey, 2009).

There is evidence that student-athletes have higher levels of EI than the general population (Saur, Desmond, \& Heintzelman, 2013). Such evidence aligns with the supposed outcomes of sport participation. Many have argued that all genuine learning comes from experience (Beard \& Wilson, 2006) and sport provides an experience not to be duplicated in society (Danish, 1983). Yet it remains to be tested if participation in sport itself leads to the development of EI. R. Feezell (2015) articulated that the end goal of sport organizations is the realization of mission-based objectives. While optimal performance in collegiate athletics is a worthy aspiration, a surfeit focus on such serves as the primary root of the aforementioned academic-athletic disconnect at so many institutions of higher education.

This research endeavor assessed a newly conceptualized version of what R. Feezell (2015) termed "the Education Argument". Rather than focus on moral education, physical development, or life skills, this investigation had a focus central to the educational missions of NCAA Division III liberal arts institutions. The purpose of this study was to use the construct of EI to quantify student-athlete development that occurs through participation in collegiate sport. Through analyzing the patterns of a student athlete's natural EI development due to such participation, one can assess the validity of the rhetoric surrounding collegiate sport participation. Studies showing that certain educative practices can develop one's EI (e.g., Boyatzis, Stubbs, \& Taylor, 2002; Crombie, Lombard, \& Noakes, 2011) are crucial to the rationale of our exploration. Understanding the level of EI development that currently occurs from participation in collegiate athletics is vital to ensure sports' potential to be used as part of a curriculum to foster the holistic development of an institution's student-athletes and prepare them as leaders for their communities. An additional aim of this research is to provide data that can help 
athletics become a collaborative unit in student development, rather than an autonomous element often in conflict with other institutional components.

The study examined four central questions:

(1) Is there a difference in Emotional Intelligence between student-athletes and non student-athletes?

(2) Does Emotional Intelligence develop over time throughout a college student's experience?

(3) Is there a difference in the development of Emotional Intelligence between those that participate in collegiate sport and those that do not? (4) Does the development of Emotional Intelligence occur differently based on the social environment (leadership, norms, ethos, and conditions) of a particular team on which one participates?

\section{Review of Literature}

Various scholars have pointed to Gardner's theory of multiple intelligences, particularly his discussions on intrapersonal and interpersonal intelligences, as truly providing the foundation for the construct of EI (Mayer, Caruso, \& Cherkasskiy, 2011; Schutte et al., 1998). Salovey and Mayer (1990) first coined the term "emotional intelligence" as a way to describe one's capability to internalize and adjust affective information - defined as "the ability to perceive and express emotion, assimilate emotion into thought, understand and reason with emotion, and regulate emotion in the self and others" (Mayer, Salovey, \& Caruso, 2000, p. 396).

Since, the term has been used to denote quite different conceptualizations of the construct, differing in agreement on key competencies and even definitions (Mayer et al., 2011). In fact, many scholars begin a review of literature on the topic by contrasting the seemingly conflicting conceptualizations of Trait EI and Ability EI (e.g. Petrides, Frederickson, \& Furnham, 2004). The ability conceptualization of EI describes one's capacity to deal with emotional information (Caruso, 2004). Instruments that measure this conceptualization are meant to gauge one's actual ability rather than an individual perception of ability. The most pragmatic critique of Ability EI is that simply possessing ability does little to ensure that the ability is consistently used. Additionally, the idiosyncratic emotions of the test-taker cannot be captured by discerning correct responses (Van Rooy \& Viswesvaran, 2007). The Trait conceptualization is typically described as a constellation of behavioral dispositions and self-perceptions concerning emotional information (Petrides et al., 2004). Critics of Trait EI profess that individual qualities encompassed in the conceptualization are more closely aligned with measures of personality (Mayer et al., 2011). Assessments of EI that combine specific mental abilities with personal traits or characteristics are termed mixed models of EI. 
Some scholars have recently described competing measures of EI more as complementary dimensions of an overall construct (Schutte, Malouff, \& Bhullar, 2009). Mikolajczak (2009) professed the merits of multiple perspectives and advocated for a unified model that assesses what one knows, what they can do, and what they actually do with emotional information. Schutte and Malouff (2013) also proposed a dimensional model of EI professing that the aforementioned perspectives are inter-related components of adaptive emotional functioning. A validated comprehensive model however does not yet exist and to date, there is not a firmly agreed upon definition of EI across disciplines.

Yet the construct of EI has been extensively researched and detailed in meta-analyses, between EI and leadership (Mills, 2009), occupational success (Joseph \& Newman, 2010; O’Boyle, Humphrey, Polack, Hawver, \& Story, 2011), overall health (Schutte, Malouff, Thorsteinsson, Bhullar, \& Rooke, 2007), and personal relationships (Schutte et al., 2001). Such research has served to combine a multitude of studies that have examined the construct of EI from all competing perspectives. Regardless of the field, scholars have generated evidence in support of the claim that higher levels of EI in individuals are directly related to positive performance and outcome measures (Schutte \& Malouff, 2013).

\section{EI and Higher Education}

Various members of a college or university community have different goals and employ different definitions of success within their units. Yet regardless of the focus of an institution, certain data (e.g., student retention, scholastic achievement, health and wellbeing, employability, and postgraduate success) is universally recorded and has been deemed essential to carrying out institutional missions.

According to Lam and Kirby (2002), a student's EI can uniquely explain individual cognitive-based performance beyond the level attributed to their general intelligence (IQ). Others have provided evidence of EI's discriminant validity in predicting academic grades over measures of Big Five personality, general intelligence, and social competence (Márquez, Martín, \& Brackett, 2006). Vela (2007) found that EI scores accounted for a higher degree of variance in first year college achievement than did SAT scores.

Scholarship has related EI to many criterions of student health and wellbeing. Examining 44 effect sizes that included nearly 8,000 participants, Schutte et al (2007) described a positive association between EI and mental health $(r$ $=.29)$, psychosomatic health $(r=.31)$, and physical health $(r=.27)$. The researchers theorized that a person's ability to perceive, understand, and manage emotions determined the extent that they would experience health related issues. Houghton, Wu, Godwin, Neck, 
and Manz (2012) described the collegiate population as one that is particularly prone to high levels of stress. Individuals with higher levels of EI appear better equipped to manage such stress (Arora et al., 2011). Whitney (2010) produced evidence that High EI students have a stronger support network of "safe adults" to assist with coping and transition issues. Song et al. (2010) directly related EI to the quality of social interaction with peers in a university setting. A negative correlation between EI and various types of maladaptive functioning and deviant behavior (e.g., binge drinking and alcohol dependence) has also been recognized (Schutte, Malouff, \& Hine, 2011). Overall, substantial evidence indicates that EI helps with holistic student-adjustment to higher education.

Studies (e.g., Qualter, Whiteley, Morley, \& Dudiak, 2009; Schutte \& Malouff, 2002) have utilized an intervention embedded into a transition course to improve student EI. Schutte and Malouff implemented specific curriculum for incoming freshman in a semester-long course. Qualter et al. applied a shorter-term transition course (one week in duration) in the summer prior to the start of the academic year. In both cases, development of EI occurred in the experimental groups and retention of the students partaking in the EI curriculum was significantly higher than a control group.

If a student was concerned about obtaining employment and having strong earning potential after graduation, var- ious scholars would advise a concerted effort to develop EI. In short, individuals with high EI have been deemed to be more employable (Pool \& Qualter, 2013) and more likely to flourish in the workplace (Nelis et al., 2011).

\section{EI and Sport}

Numerous theories have been presented and tested related to how athletes deal with emotions and arousal (e.g., Hanin, 2000). It generally follows that emotions play a crucial role in sport performance. The exact nature of emotions in sport performance and why individual athletes seem to be uniquely impacted remain less clear (Sough et al., 2009). Despite the sincere interest in emotions and sport performance, the construct of EI has only been studied in the context of sport on a few occasions (Stough, Saklofske, \& Parker, 2009). Theoretically advocating for the inclusion of studying EI in sport psychology, Perlini and Halverson (2006) stated, "[elite sport] requires the effective management of stress, tolerance of frustration, regulation of mood, and exercise of emotional restraint, within public purview and scrutiny" ( $p$. 3). However, like many other scholarly disciplines, researchers in sport have lacked a standardized approach to inquiry with inconsistent conceptualizations of EI and different assessment procedures (Meyer \& Fletcher, 2007). Without substantial expertise in EI, researchers in sport performance and psychology have likely been stymied in their exploration of EI's utility. 
Crombie et al. (2009) fist examined the relationship between EI and winning in a team environment. They assessed the EI of individuals on six cricket teams competing in the South African national cricket competition over two consecutive seasons establishing Team EI to be a significant predictor of sports performance. Due to the demonstrated positive relationship, Crombie et al. (2011) imparted an intervention designed to develop EI among elite Cricketers. Similarly, Ajayi \& Fatokun (2008) employed an EI intervention to amateur athletes in various Nigerian national programs. Results of both interventions indicated that EI training has potential to be effective in a population of elite athletes. To date, there have not been any studies that have examined whether or not EI is developed through participation in sport.

\section{METHOD}

\section{Sampling Method and Subject Description}

The population of interest to the researchers were selective, residential, liberal arts institutions that participate in NCAA Division III. The outcomes from participation in sport in this environment affect a sizable portion of the student population. Emerson et al. (2009) explained that with an average enrollment of 2,250, as much as a third or more of the students at liberal arts colleges are listed on a varsity roster. Because liberal arts institutions claim distinction in holistically developing competencies of their students - which includes educating students outside of the classroom - determining if sport is currently educating student-athletes in such a manner is particularly important at such institutions.

The sample consisted of all winter sport athletes (i.e., Men's and Women's Basketball, Men's and Women's Swimming \& Diving, and Men's and Women's Indoor Track and Field) from five liberal arts institutions that participate in a like-minded athletic conference of academically selective liberal arts colleges and universities. Member institutions share a similar mission, strong academic focus, and similar institutional characteristics. The 5 institutions comprising the study sample represented half of the 10 institutions with conference membership. Each institution within the study sample fit into the definition of a liberal arts college (Blaich, Bost, Chan, \& Lynch, 2006; National Liberal Arts College Rankings, 2016).

In order to secure support from sample institutions, the researchers contacted all Athletic Directors within the conference to discuss the study proposal and gauge interest. Five Athletic Directors expressed interest in participation. After electronic correspondence and phone conversations, the researchers completed site visits at the five interested institutions. In each case, Athletic Directors pledged support as far as informing and encouraging coaching staffs under their direction to promote participation among student-athletes. Athletic Directors were continuously informed with the study 
progress so that reminders to coaches and student athletes could be generated internally as well as coming directly from the researchers.

In total, the student enrollment at the 5 participating institutions was 9,409. Based on team rosters available on institutional websites, approximately 3,000 students were classified as varsity athletes, 750 having participated in winter sports the previous year (experimental group). There were 776 individuals that completed the initial instrument, representing all five institutions, the aforementioned winter sports, and all four class years. (See Table 1 and Table 2). The posttest was completed by 336 individuals. Participation in the competitive season served as the natural intervention for this research. It was therefore determined that non-winter sport athletes should be excluded from the analysis. These athletes, while not technically "in-season", would still have contact with their coaches and teammates, complete pre-season and post-season voluntary or captain- led workouts, and participate in team activities (e.g., bonding activities and community service). Such important aspects of sport participation could potentially develop EI. Since non winter-sport athletes would be receiving aspects of the natural intervention during the timeframe of the research, their experience would not fit into either the control group (non-athletes) or the experimental group (in-season athletes).

\section{Instrument}

This research utilized a pre-established instrument - the Assessing Emotions Scale (AES). Schutte's AES has been referred to in literature by additional names: The Emotional Intelligence Scale (EIS), The Self-Report Emotional Intelligence Test (SREIT), and the Schutte Emotional Intelligence Scale (SEIS). Unlike many instruments of EI, the AES is not property of a consulting group and is considered public domain for scholarly purposes with permission

Table 1

Pretest Responses by Institution

\begin{tabular}{ccccc}
\hline Institution & Emails Sent & Responses & Response Rate & $\begin{array}{c}\text { Percent of } \\
\text { Sample }\end{array}$ \\
\hline 1 & 577 & 129 & $22.4 \%$ & $16.6 \%$ \\
2 & 843 & 29 & $3.4 \%$ & $3.7 \%$ \\
3 & 964 & 175 & $18.2 \%$ & $22.6 \%$ \\
4 & 863 & 114 & $13.2 \%$ & $14.7 \%$ \\
5 & 1722 & 329 & $19.1 \%$ & $42.4 \%$ \\
\hline Total & 4969 & 776 & $15.6 \%$ & $100 \%$
\end{tabular}


Table 2

Pretest Responses by Sport

\begin{tabular}{lcc}
\hline Athletic Team & $N$ & Percent of Sample \\
\hline M Basketball & 40 & $5.1 \%$ \\
W Basketball & 20 & $2.6 \%$ \\
M Swim/Dive & 24 & $3.1 \%$ \\
W Swim/Dive & 35 & $4.5 \%$ \\
M Track & 33 & $4.3 \%$ \\
W Track & 36 & $4.6 \%$ \\
Other (Non-Winter Sports) & 204 & $26.3 \%$ \\
No Varsity Sport (Control) & 383 & $49.4 \%$ \\
\hline Total & 776 & $100 \%$
\end{tabular}

from the author. The AES is one of the most commonly used measures of EI in scientific literature (Schutte et al., 2009) and was employed in some of the very few studies that have measured emotional intelligence in the context of sport (Lane, Thelwell, Lowther, \& Devonport 2009; Thelwell, Lane, Weston, \& Greenlees, 2008; Zizzi, Deaner, \& Hirschhorn 2006). With the scale so frequently used, substantial psychometric information is available. Additionally, multiple studies have demonstrated that EI, established through the AES, can be developed over time and through interventions (Qualter, et al., 2009; Schutte \& Malouff, 2002).

Schutte et al. (1998) initially generated a pool of 62 test items based on Salovey and Mayer's (1990) theoretical model of EI. They then completed a principal-components, orthogonal-rotation, factor analysis of participant responses. The study authors reported a first-factor eigenvalue of 10.79 with 33 scale items loading on the first factor at 0.40 or above. The 33 items that loaded on factor one represented all portions of the conceptual model utilized in the instrument creation (Schutte et al.). Because of the strength of factor one and the adherence of the 33 items to the components of the conceptual model, the researchers elected to use the 33 items for the final version of the scale (Schutte et al). While others have suggested the scale contains multiple factors of EI (Lane et al., 2009; Petrides \& Furnham, 2000), the instrument authors contended that based on a factor analysis, the AES measures a single general EI factor (Schutte, et al., 2011).

Shutte's 33-item self-report scale is unique in that it that does not present ability and trait conceptualizations of EI as mutually exclusive alternatives, but rather complimentary dimensions of the construct (Schutte et al., 2009). Schutte (2014) detailed her conceptualization of EI of consisting of four branches: 
(1) perceiving emotions - recognizing emotional cues in the self and others; (2) understanding emotions - the knowledge of the causes and complexities of emotional experience in the self and others; (3) managing emotions - being able to effectively regulate emotions in the self and others; and (4) harnessing emotions - drawing on emotion to achieve goals, such as solving problems.

The AES asks participants to judge themselves on a five-point Likert scale. For example, "I know when to speak to another person about my problems", rated from 1 (never) to 5 (consistently). The total EI score is derived from summing up item responses. According to Schutte et al. (2009), respondents require an average of five minutes to complete the scale with scores ranging from 33 to 165 . Higher scores indicate a more developed level of EI.

The present study included additional questions designed to capture demographic information such as a participant's institution and sport participation. Those that reported playing a winter sport were placed in the experimental group, while those that did not were placed in the control group. Fall and spring-sport athletes were not included in either the experimental or control group.

\section{Instrument Reliability}

The composite AES score, a measure of uni-dimensional EI, is derived from 33 scale items. In order to test the internal consistency associated with the composite score, Cronbach's Alpha was tested on all scale items of the AES in both the pretest and the posttest data. A commonly cited recommendation of "good internal consistency" is a Cronbach's Alpha score of at least .80 (Henson, 2001). Such a score presents strong evidence that it is justifiable to interpret scores that have been aggregated together (i.e., The Total AES Score). Cronbach's Alpha on the 33-item AES for the pretest data $(N=776)$ was .83 . Posttest data revealed a Cronbach's Alpha of .85 on the sample size $(N=335)$. Similar with the pretest data, the inter-item correlation matrix provided evidence that all scale items should be included.

\section{Data Collection}

The research was approved by Institutional Review Board (IRB) at the researchers' host university, as well as the IRBs of each research site. Due to additional ongoing research at Institution \#1, the Director of Institutional Research decided that only a random sample of students would be solicited for the control group (500 students). Similarly, Institution \#3 allowed for a randomly generated pool of approximately 900 students to serve as a control. In each case, an email distribution of the random sample was provided to the researchers for solicitation. At Institution \#2, Institution \#4, and Institution \#5, the Director of Institutional Research provided the researchers with an email distribution list of the entire student body. 
An initial contact email was generated to all students that were to partake in the research at each sample institution, informing students about the nature of the research and the amount of time needed to complete both the pretest and posttest. A follow-up email was transmitted to the distribution list five days later officially inviting students to participate in the research. The email contained a link to the AES loaded on Qualtrics. Students were ensured confidentiality but were made aware that an identifier would be needed to be able to compare pretest posttest scores. Two reminder emails were sent to prospective participants in one-week intervals with a final reminder sent 24 hours before the closing of the study survey. The survey was closed at each institution prior to the official start of the competitive winter sport seasons.

All participants that completed the pretest were then contacted after the winter sports seasons with a link to the posttest. Identical follow-up email procedures were followed for the posttest. The timing of the pretest and posttest allowed for a five-month natural intervention of sport participation to occur.

\section{Data Analysis}

Two separate forms of data analysis were conducted, both categorized as Repeated-Measures ANOVA. The model used for Research Questions \#1 and \#3 was a Three-factor Split-Plot Repeated-Measures ANOVA, which included one repeated factor (time) and two non-repeated factors (institution and sport + control). To address Research Question \#2, it was necessary to look at all student-athletes that participated in the experimental group as a single group compared to the control group (non-student athletes). Data was therefore recoded for a Two-factor Split-plot Repeated Measures ANOVA.

\section{Results}

\section{Pretest Data}

Descriptive data was taken on each subject to differentiate their institution and their athletic affiliation. The numbers of students contacted, response rates, and the percentages of the total sample associated with the categorical variable Institution are represented in Table 1. Table 2 displays frequencies for the categorical variable Sport. All descriptive data discussed and represented in forthcoming tables was already cleaned; missing data had been imputed and univariate outliers had been removed. The total rate of response for this study was $15.6 \%$.

The sample distribution was relatively evenly split between athletes $(50.6 \%)$ and non-athletes (49.4\%). Roughly half of the varsity athletes that responded to the survey ( $24.3 \%$ of total respondents) could be placed in the experimental group based on their affiliation with Men's and Women's Basketball, Men's and Women's Indoor Track, and Men's and Women's Swimming and Diving. The remainder of the responding varsity athletes $(26.3 \%)$ identified with a non-winter sport. Only athletes participating in one 
of the aforementioned winter sports were placed in the experimental group.

Initial Differences. The researchers were interested in whether there were initial differences in population means. The researchers conducted a two-factor ANOVA to determine if there was a mean difference in the Total AES Scores between students at the five institutions and between the sports in which they participated. Descriptive statistics of the dependent variable can be seen in Table 3. There was no main effect for either independent variable $\left(F_{\text {Institution }}=.495\right.$, $d f=4,743, p=.739 ; F_{\text {Sport }}=1.376, d f=$ $7,43, p=.212)$. Nor was there an interaction effect $\left(F_{\text {Institution*Sport }}=1.439, d f\right.$ $=20,743, p=.096)$. For example, male basketball players did not have a significantly different mean AES Total Score than female swimmers, non-athletes, etc., nor was there a significant difference in mean AES Total Score between any institutions. Finally, there lacked a joint effect of both factors on the dependent variable. Without a statistically significant omnibus ANOVA $F$ test, a post hoc analysis was not necessary.

According to Saur et al. (2013), there is evidence that subpopulations of students (i.e., student-athletes and students involved in Greek Life) have higher levels of EI compared to the general population of students. Because the researchers were foremost concerned with whether or not sport can develop EI, there was interest in examining such claims. Data was recoded to combine all student-athletes into one group $(N=392)$ to con- duct a one-sample $t$-test. Student-athletes had a mean AES Total Score of 128.06 $(S D=12.53)$, while non-athletes had a mean score of $125.65(S D=15.47)$. The one-sample $t$-test was statistically significant $(t=2.38, d f=737.34, p=.017)$. This provided evidence to suggest that the mean AES score of student-athletes was significantly higher than that of non-athletes on the pretest. While the effect size was considered small (.20), a post hoc power analysis was 1.00 .

\section{Posttest Data}

Participants that completed the pretest instrument were invited to retake the instrument approximately five months later, after winter sport athletes had completed their competitive season. Identical procedures were followed in the collection of the posttest data. Approximately $43 \%$ of pretest respondents completed the posttest as well $(N=336)$. The experimental group of winter sport athletes had a posttest completion rate of $45.8 \%$ $(n=86)$, while the control group of non-student athletes had a $47.3 \%$ completion rate $(n=181)$.

Posttest data was scanned for univariate outliers. $Z$ scores were generated and examined in accordance with the three-sigma rule (Tabachnick \& Fidell, 2013). No univariate outliers for the variable Total AES Score were present in the posttest data. Survey data of varsity athletes of non-winter sports $(n=68)$ was removed leaving a final sample for analysis was 267. Descriptive data is rep- 
Table 3

Descriptive Statistics of the DV: Total AES Score (Pretest)

\begin{tabular}{|c|c|c|c|c|}
\hline Current Team & Institution & Mean & $S D$ & $N$ \\
\hline \multirow[t]{6}{*}{ M Basketball } & 1 & 132.50 & 10.247 & 4 \\
\hline & 2 & 126.27 & 17.182 & 11 \\
\hline & 3 & 95.00 & - & 1 \\
\hline & 4 & 131.06 & 9.833 & 17 \\
\hline & 5 & 122.43 & 11.928 & 7 \\
\hline & Total & 127.48 & 13.621 & 40 \\
\hline \multirow[t]{4}{*}{ W Basketball } & 1 & 130.14 & 15.356 & 7 \\
\hline & 3 & 125.75 & 13.401 & 4 \\
\hline & 5 & 130.22 & 10.918 & 9 \\
\hline & Total & 129.30 & 12.503 & 20 \\
\hline \multirow[t]{5}{*}{ M Swim/Dive } & 1 & 128.18 & 11.902 & 17 \\
\hline & 3 & 125.00 & 13.077 & 3 \\
\hline & 4 & 128.00 & - & 1 \\
\hline & 5 & 131.33 & 5.132 & 3 \\
\hline & Total & 128.17 & 10.877 & 24 \\
\hline \multirow[t]{4}{*}{ W Swim/Dive } & 1 & 122.08 & 12.638 & 12 \\
\hline & 3 & 128.75 & 20.457 & 8 \\
\hline & 5 & 127.93 & 11.75 & 15 \\
\hline & Total & 126.11 & 14.266 & 35 \\
\hline \multirow[t]{5}{*}{ M Track } & 1 & 121.43 & 7.323 & 7 \\
\hline & 3 & 140.20 & 10.378 & 5 \\
\hline & 4 & 122.86 & 14.491 & 14 \\
\hline & 5 & 130.00 & 9.238 & 7 \\
\hline & Total & 126.7 & 12.97 & 33 \\
\hline \multirow[t]{4}{*}{ W Track } & 1 & 131.19 & 13.561 & 16 \\
\hline & 3 & 128.50 & 11.085 & 14 \\
\hline & 5 & 121.00 & 11.454 & 6 \\
\hline & Total & 128.44 & 12.496 & 36 \\
\hline \multirow[t]{6}{*}{ Other } & 1 & 133.29 & 8.915 & 17 \\
\hline & 2 & 135.67 & 18.009 & 3 \\
\hline & 3 & 128.52 & 12.139 & 65 \\
\hline & 4 & 124.54 & 14.043 & 26 \\
\hline & 5 & 128.55 & 11.941 & 93 \\
\hline & Total & 128.53 & 12.227 & 204 \\
\hline
\end{tabular}

Journal of Amateur Sport $\quad$ Volume Four, Issue Three $\quad$ Lott and Turner, 2018 
Table 3 Continued

\begin{tabular}{ccccc}
\hline Current Team & Institution & Mean & $S D$ & $N$ \\
\hline No Varsity Sport & 1 & 126.04 & 15.793 & 49 \\
& 2 & 120.27 & 14.733 & 15 \\
& 3 & 122.85 & 15.458 & 75 \\
& 4 & 126.66 & 14.836 & 56 \\
Total & 5 & 127.10 & 15.217 & 188 \\
& Total & 125.80 & 15.313 & 383 \\
\hline & 1 & 127.72 & 13.616 & 129 \\
& 2 & 124.14 & 16.162 & 29 \\
& 3 & 126.12 & 14.429 & 175 \\
& 4 & 126.38 & 13.939 & 114 \\
& 5 & 127.52 & 13.781 & 328 \\
\hline & Total & 126.94 & 14.009 & 775
\end{tabular}

resented in Tables 4 and 5. Sample sizes, means, and standard deviations of Total AES Score by Institution and Current Team are represented in Table 6.

Results of the Three-factor Split-plot Repeated Measures ANOVA indicated a significant main effect for the within subjects, or repeated factor of time $(F$ $=6.503, d f=1,246, p=.011)$. Pertaining to Research Question \#2 - whether students develop EI throughout their college experience - the significant main effect for time suggests that there is a mean difference in Total AES Score between the pretest and posttest. Sufficient power (.719) was observed (Lomax $\&$ Hahs-Vaughn, 2012). The effect size was however small (Partial $\eta^{2}=.026$ ). Cohen (1988) explained that a small effect size (Partial $\eta^{2}<.06$ when using ANOVA) demonstrates a minimal overall effect, or practical significance. Research Question \#3 was principally concerned with differences in EI development between specific athletic teams. ANOVA results demonstrated the following: (1) A lack of interaction effect between Time and Team $(F=.873, d f=6,246$, $p=.516)$; and (2) A lack of interaction effect between Time, Team, and Current Institution $(F=.420, d f=10,246, p=$ .936). Each interaction, however, lacked sufficient power $\left(\right.$ Time ${ }^{*}$ Current Team $=$ .343 and Time*Institution*Current Team $=.217)$. The lack of power indicates a possibility of a larger sample producing a significant interaction effect (Lomax \& Hahs-Vaughn). Testing for contrasts of the within subject factor through Multiple Comparison Procedures (MCPs) was not necessary because there were only two levels of the factor. The significant 
Table 4

Total Responses by Institution

\begin{tabular}{ccccc}
\hline Institution & Pretest $N$ & Final $N$ & $\begin{array}{c}\text { Posttes } \\
\text { Response Rate }\end{array}$ & $\begin{array}{c}\text { Percent of } \\
\text { Sample }\end{array}$ \\
\hline 1 & 129 & 72 & $55.8 \%$ & $27.0 \%$ \\
2 & 29 & 11 & $37.9 \%$ & $4.1 \%$ \\
3 & 175 & 62 & $35.4 \%$ & $23.2 \%$ \\
4 & 114 & 38 & $33.3 \%$ & $14.2 \%$ \\
5 & 329 & 84 & $25.5 \%$ & $31.5 \%$ \\
\hline Total & 776 & 267 & $34.4 \%$ & $100.0 \%$
\end{tabular}

Table 5

Total Responses by Team

\begin{tabular}{lcccc}
\hline Current Team & Pretest $N$ & Final $N$ & $\begin{array}{c}\text { Posttest } \\
\text { Response Rate }\end{array}$ & $\begin{array}{c}\text { Percent of } \\
\text { Sample }\end{array}$ \\
\hline M Basketball & 40 & 9 & $22.5 \%$ & $3.4 \%$ \\
W Basketball & 20 & 12 & $60.0 \%$ & $4.5 \%$ \\
M Swim/Dive & 24 & 8 & $33.3 \%$ & $3.0 \%$ \\
W Swim/Dive & 35 & 18 & $51.4 \%$ & $6.7 \%$ \\
M Track & 33 & 15 & $45.5 \%$ & $5.6 \%$ \\
W Track & 36 & 24 & $66.7 \%$ & $9.0 \%$ \\
Control & 383 & 181 & $47.3 \%$ & $67.8 \%$ \\
\hline Total & 571 & 267 & $46.8 \%$ & $100.0 \%$
\end{tabular}

Note: Pretest $\mathrm{N}$ in this chart is smaller because non-winter sport athletes were removed from the total pretest sample of 776 .

$F$ statistic could therefore only indicate

a difference between Time 1 and Time 2 (the pretest and posttest).

The results from tests of between-subject effects (non-repeated factors) showed the main effect of Current Team was non-significant $(F=.904$, $d f=6,246, p=.492)$. Additionally, there was no interaction effect between Institution and Current Team $(F=.502, d f$ $=10,246, p=.888)$. By examining the pairwise contrasts of independent variables, substantial overlap can be observed within their 95\% Confidence Intervals. Similar to results of the within-subjects test, power was not sufficient (Current 
Table 6

Descriptive Statistics

\begin{tabular}{|c|c|c|c|c|c|}
\hline & Institution & Current Team & Mean & $S D$ & $N$ \\
\hline \multirow[t]{34}{*}{ Pretest } & \multirow[t]{7}{*}{1} & W Basketball & 125.60 & 15.566 & 5 \\
\hline & & M Swim/Dive & 129.29 & 14.986 & 7 \\
\hline & & W Swim/Dive & 120.83 & 10.167 & 6 \\
\hline & & M Track & 121.83 & 7.935 & 6 \\
\hline & & W Track & 132.77 & 12.584 & 13 \\
\hline & & Control & 123.97 & 13.906 & 35 \\
\hline & & Total & 125.75 & 13.374 & 72 \\
\hline & \multirow[t]{3}{*}{2} & M Basketball & 120.00 & 21.783 & 5 \\
\hline & & Control & 125.50 & 12.161 & 6 \\
\hline & & Total & 123.00 & 16.492 & 11 \\
\hline & \multirow[t]{7}{*}{3} & W Basketball & 122.67 & 14.572 & 3 \\
\hline & & M Swim/Dive & 140.00 & - & 1 \\
\hline & & W Swim/Dive & 126.00 & 21.954 & 6 \\
\hline & & M Track & 120.50 & 10.607 & 2 \\
\hline & & W Track & 129.90 & 11.14 & 10 \\
\hline & & Control & 119.58 & 16.232 & 40 \\
\hline & & Total & 122.37 & 16.000 & 62 \\
\hline & \multirow[t]{4}{*}{4} & M Basketball & 129.00 & 7.071 & 4 \\
\hline & & M Track & 119.14 & 18.28 & 7 \\
\hline & & Control & 127.07 & 14.09 & 27 \\
\hline & & Total & 125.82 & 14.437 & 38 \\
\hline & \multirow[t]{5}{*}{5} & W Basketball & 126.5 & 9.983 & 4 \\
\hline & & W Swim/Dive & 131.83 & 14.261 & 6 \\
\hline & & W Track & 127.00 & - & 1 \\
\hline & & Control & 124.41 & 15.568 & 73 \\
\hline & & Total & 125.07 & 15.163 & 84 \\
\hline & \multirow[t]{8}{*}{ Total } & M Basketball & 124.00 & 16.688 & 9 \\
\hline & & W Basketball & 125.17 & 12.503 & 12 \\
\hline & & M Swim/Dive & 130.63 & 14.382 & 8 \\
\hline & & W Swim/Dive & 126.22 & 15.917 & 18 \\
\hline & & M Track & 120.40 & 13.244 & 15 \\
\hline & & W Track & 131.33 & 11.578 & 24 \\
\hline & & Control & 123.69 & 15.138 & 181 \\
\hline & & Total & 124.65 & 14.809 & 267 \\
\hline
\end{tabular}

Journal of Amateur Sport $\quad$ Volume Four, Issue Three $\quad$ Lott and Turner, $2018 \quad 16$ 
Table 6 Continued

\begin{tabular}{|c|c|c|c|c|c|}
\hline & Institution & Current Team & Mean & $S D$ & $N$ \\
\hline \multirow[t]{34}{*}{ Posttest } & \multirow[t]{7}{*}{1} & W Basketball & 130.20 & 11.278 & 5 \\
\hline & & M Swim/Dive & 130.71 & 14.009 & 7 \\
\hline & & W Swim/Dive & 124.50 & 11.131 & 6 \\
\hline & & M Track & 126.33 & 6.439 & 6 \\
\hline & & W Track & 136.62 & 16.566 & 13 \\
\hline & & Control & 126.17 & 13.644 & 35 \\
\hline & & Total & 128.65 & 13.714 & 72 \\
\hline & \multirow[t]{3}{*}{2} & M Basketball & 123.60 & 15.726 & 5 \\
\hline & & Control & 128.50 & 12.470 & 6 \\
\hline & & Total & 126.27 & 13.536 & 11 \\
\hline & \multirow[t]{7}{*}{3} & W Basketball & 125.33 & 5.033 & 3 \\
\hline & & M Swim/Dive & 154.00 & - & 1 \\
\hline & & W Swim/Dive & 125.67 & 16.367 & 6 \\
\hline & & M Track & 123.50 & 9.192 & 2 \\
\hline & & W Track & 128.50 & 9.312 & 10 \\
\hline & & Control & 120.20 & 16.929 & 40 \\
\hline & & Total & 122.97 & 15.717 & 62 \\
\hline & \multirow[t]{4}{*}{4} & M Basketball & 129.75 & 18.679 & 4 \\
\hline & & M Track & 126.00 & 11.776 & 7 \\
\hline & & Control & 129.78 & 12.945 & 27 \\
\hline & & Total & 129.08 & 13.066 & 38 \\
\hline & \multirow[t]{5}{*}{5} & W Basketball & 136.25 & 12.659 & 4 \\
\hline & & W Swim/Dive & 130.67 & 18.151 & 6 \\
\hline & & W Track & 125.00 & - & 1 \\
\hline & & Control & 124.03 & 15.712 & 73 \\
\hline & & Total & 125.10 & 15.781 & 84 \\
\hline & \multirow[t]{8}{*}{ Total } & M Basketball & 126.33 & 16.279 & 9 \\
\hline & & W Basketball & 131.00 & 10.660 & 12 \\
\hline & & M Swim/Dive & 133.63 & 15.362 & 8 \\
\hline & & W Swim/Dive & 126.94 & 14.822 & 18 \\
\hline & & M Track & 125.80 & 9.010 & 15 \\
\hline & & W Track & 132.75 & 14.001 & 24 \\
\hline & & Control & 124.60 & 15.296 & 181 \\
\hline & & Total & 126.18 & 14.860 & 267 \\
\hline
\end{tabular}

Note. Only those that completed both the pretest and posttest are included in the table. 
Team $=.356$, and Interaction $=.259)$. All pairwise comparisons as calculated through Tukey Honestly Significant Difference (HSD) were also non-significant.

In order to address Research Question \#3 - whether or not there is a significant difference in the development of EI between athletes and non-athletes - data was recoded with all student-athletes from the experimental group placed into a single group. The final sample consisted of 86 winter sport athletes and a control group of 181 (students that do not participate in varsity sport). A Two-factor Split-plot Repeated Measures ANOVA was executed. Descriptive statistics are displayed in Table 7 . The ANOVA provided evidence of a significant main effect of sport participation regarding Total AES Scores $(F=4.707$, $d f=1,265, p=.031$, with medium power (observed power $=.580)$ and small effect size (Partial $\eta 2=.017)$. However, results indicated the interaction effect between time and the whether or not one was a student-athlete (experimental versus control) was non-significant $(F=$
2.047, $d f=1,265 \mathrm{p}=.154)$. Low power was observed (observed power $=.297$ ).

\section{Discussion}

The foremost aim of our research was to gain insight on whether participation in collegiate athletics - in the context of the selective, residential, liberal arts - is serving to fulfill institutional missions, missions that are distinct within higher education (Seifert et al., 2008). The interdisciplinary nature and focus on holistic student development at these institutions necessitates an educational contribution from athletic participation. If student-athletes are not enhancing their emotional and social competencies, a primary reason for sport's presence is not supported.

Bouchet and Hutchinson (2011) explained that financial resources are limited; a comprehensive athletics program requires a substantial commitment from the institution, and the operating costs of doing so are continuously rising. Between 2004 and 2014, Division III institutions added an average of between 53 and

Table 7

Descriptive Statistics -Student-Athletes Versus Non-Athletes

\begin{tabular}{lllll}
\hline & & Mean & $S D$ & $N$ \\
\hline Pretest & Athlete & 126.66 & 13.963 & 86 \\
& Non-Athlete & 123.69 & 15.138 & 181 \\
& Total & 124.65 & 14.809 & 267 \\
\hline Posttest & Athlete & 129.49 & 13.386 & 86 \\
& Non-Athlete & 124.60 & 15.296 & 181 \\
& Total & 126.18 & 14.860 & 267 \\
\hline
\end{tabular}


90 new student-athletes (depending on the presence of a football program) and increased the average cost per athlete by roughly $\$ 6,000$ (Fulks, 2015). Significant program expenditures from colleges and universities become more difficult to justify when accounts of positive benefits to the educational mission and development of students are strictly anecdotal and unsupported with empirical evidence. A rift between academic and athletic units throughout higher education, especially at academically rigorous institutions, has been noted (Aries et al., 2004; T. Feezell, 2015; Lytle, 2003). Not coincidentally, there has lacked assessment of whether sport develops participants in a manner that specifically pertains to institutional missions.

In order to address the challenge, the researchers employed the construct of EI; competencies that are encompassed in the construct are central to the educational missions of such institutions. Previous scholarship had yet to explore the theoretical linkages between the rhetoric of student development through athletic participation, EI, and the educational missions of the selective, residential, liberal arts. This investigation has therefore examined the educational impact of participation in collegiate athletics in a unique manner.

The ability to develop EI through unique curriculums and pedagogies (e.g., Boyatzis et al., 2002) and specific interventions (e.g., Crombie et al., 2011) is well-documented. Yet most forms of systematic experimental research examin- ing the development of EI within institutions of higher education have employed very brief EI interventions, thus not assessing a control group for an extended duration (e.g., Qualter et al., 2009). Three studies in the field have however assessed the development of EI through an intervention over a duration comparable to the present research (Clark, Callister, \& Wallace, 2003; Nelis et al., 2011; Schutte $\&$ Malouff, 2002). In each case, only the experimental groups demonstrated a significant improvement in EI; each control group's EI remained static.

Students in the present study population as a whole increased their level of EI over a five-month time-period. Such findings appear to be the first to provide evidence that a student might develop EI through their educational experience, even over the course of a single semester. It is important to note that the study population consisted of a group of relatively comparable, selective, residential, liberal arts institutions. The context of inquiry therefore becomes quite important in the explanation of the unique results. Scholarship has demonstrated that social environments can affect the development of EI (Schutte, 2014). Both the mission and the environment at selective, residential, liberal arts institutions has been shown to be quite different from that of most institutions of higher education, producing distinctive outcomes (Seifert et al., 2008). The present study provided empirical evidence pertaining to the efficacy of the liberal arts - that such institutions are in fact fulfilling their 
academic missions through the facilitation of intrapersonal and interpersonal development.

Results also indicated that EI development occurs in a similar manner between both student-athletes and non-athletes. There was no indication of an additive effect of sport participation. Blaich et al., (2006) explained that one of the tenants of the liberal arts experience is high participation in extracurricular activities. Brand (2006) equated the educational experience of collegiate athletics with that of the performing and studio arts (i.e., music, theatre, and dance). Based on the study environment, it is reasonable to assume that participants were afforded a plethora of opportunities to engage in activities with the potential to facilitate EI development. One could then claim that the experience of participation in collegiate athletics might not uniquely develop students compared with other experiences available in this context. However, according to Danish (1983), "Sport provides an environment which is more personal, concrete, time-limited, and intense than the rest of society" ( $p$. 238). If the experience of sport is truly unique, another explanation could involve how student-athletes are engaging in the experience of sport participation.

One has to be predisposed to, or become open to, truly learning from their experiences (Beard \& Wilson, 2006). Kolb (1984) defined learning as a process of knowledge acquisition generated through the transformation of the experience (emphasis added). The process of experiential learning must be purposeful. Due to various internal or external barriers, not all experiences lead to new insights or new learning (Beard \& Wilson). Jarvis (1987) even included non-learning pathways in his model of experiential learning. While participation in collegiate athletics might provide a powerful and emotional experience (Botterill \& Brown, 2002), it is quite feasible that student-athletes are not transforming their experiences in a way to generate the development of EI on a consistent basis.

While sport's capacity to facilitate the development of EI among its participants has not previously been studied, many have attempted to discern the relationship between athletic participation and other forms of development (e.g., life skills, competencies, and positive character). In short, literature has indicated that other types of development are not "caught" through participation in athletics but must be "taught" (Danish, Petitpas, \& Hale, 2007). Similar to scholars of experiential learning, researchers that have examined various forms of personal development through sport participation (Gould \& Carson, 2008) have served to elucidate our findings. Without someone (e.g., an administrator, a coach, or leadership team) in place capable of facilitating the transformation of emotionally related experiences achieved through sport participation, consistent EI development within student-athletes is not likely to occur.

According to Gilbert and Trudel (2001), coaching knowledge and tech- 
niques are predominately developed through the observation of other coaches. It is therefore quite likely that a high degree of variance in pedagogy will be found among coaches based on their influences and exposures. The individual EI of a particular coach might also matter. Lillis (2012) provided evidence that the EI levels of persons in the role of an advisor influences behaviors of students. Regardless of the sport, student-athletes are heavily engaged in both mentoring and being mentored by coaches and teammates (Sauer et al., 2013). Schutte (2014) determined that the composite EI level of peer groups and learning-communities influence student EI development.

Regardless of the potential differences in both the environment of a particular team and various teaching pedagogies of which a student-athlete could be exposed, current study findings did not indicate that participation on a particular team influenced the development of participant EI. However, the response rate of particular teams within the study affected the analysis of this relationship (see study limitations below).

\section{Study Limitations}

Many instruments to measure EI are available. Using alternate instruments could therefore influence results. The present study was conducted in the rather unique environment of the selective, residential, liberal arts. It is unlikely that the result pertaining to the development of EI over time is generalizable to other types of institutions throughout higher education.

The timeframe in which the study was conducted limited the scope of the project. Ideally, pretest data collection would have occurred as the academic year commenced in the fall. Obtaining a baseline at this juncture would have allowed the posttest assessment to include EI development that could have occurred through team interactions outside of the competitive season such as community service projects and other team social activities. The timeframe also precluded the inclusion of fall and spring sports. Generating data on additional groups of athletes would have added to the understanding of what was transpiring.

The non-significant finding pertaining to the EI development of student-athletes on a particular team was adversely impacted by the response rate of the posttest. Because some teams were represented by small $n$ 's, less than adequate power was realized. There was therefore a low probability of finding a significant result even if one was present. Study results lacked the ability to clearly determine if a particular team was facilitating the development of EI more effectively than any other one.

\section{Principal Implication and Future Directions}

Empirical data generated from the present study has indicated that the experience of participating in collegiate athletics is not consistently and uniquely facilitating the institutional mission 
of the selective, residential, liberal arts. Sport participation does not appear to be enhancing the emotional and social competencies of student athletes more so than their collegiate experience at large. Some have argued that coaching effectiveness must be centered on maximizing an athlete's learning outcomes (Côté \& Gilbert, 2009). Collegiate sport must be operationalized in a manner that reflects institutional missions (R. Feezell, 2015). In the environment of the selective, residential, liberal arts, institutional missions and the associated student athlete learning outcomes are clear. These colleges and universities must therefore make concerted efforts to help student athletes more fully utilize the potentially powerful experience of sport participation to enhance their EI and the associated capacity to lead in a dynamic and rapidly changing world.

Much work remains to be done to ascertain how best to use sport participation to develop participant EI. There is a stated need for more systematic empirical research examining the development of EI through interventions in general (Schutte \& Malouff, 2013). While two projects have engaged in such research within sport populations (Ajayi \& Fatokun, 2008; Crombie et al., 2011), no one has attempted to introduce an EI intervention into a college sport program.

EI interventions in other contexts - as well as pedagogies that have been shown to develop EI - provide a starting point. These experiments have utilized different approaches to training and employed interventions that substantially differed in program duration. Commonalities of interventions need to be explored so that it can be determined what pedagogies can consistently enhance EI. Researchers can advance our understanding of the process by inserting EI interventions into collegiate athletics settings and measuring short-term and longitudinal changes in EI against a control group. The utility of such work could provide suggestions and procedures for collegiate athletic departments. If institutions can demonstrate the development of intrapersonal, interpersonal capacities of student athletes on a consistent basis, they will be able to both better justify current expenditures on athletics as well as work to lessen the aforementioned academic/athletic rift present on many campuses. The liberal arts will be best served if all institutional components are working in concert to maximize student development in line with stated missions.

\section{References}

Ajayi, M. \& Fatokun A. L. (2008). Effect of a six-week emotional intelligence programme on the sports performance of amateur athletes in oyo state of nigeria. Retrieved from http:// sircretriever.ca/africaresearchaward/documents/EffectofSix-WeekEmotional.pdf Aries, E., McCarthy, D., Salovey, P., \& Banaji, M. R. (2004). A comparison of athletes and non-athletes at highly selective colleges: Academic performance and personal development. 
Research in Higher Education, 45(6), 577-602.

Arora, S., Russ, S., Petrides, K.V., Sirimanna, P., Aggarwal, R., Darzi, A., \& Sevdalis, N. (2011). Academic Medicine, 86(10), 1311-1317. doi: 10.1097/

ACM.0b013e31822bd7aa

Beard, C. M., \& Wilson, J. P. (2006). Experiential learning: A best practice handbook for educators and trainers. Kogan Page Publishers.

Blaich, C.F., Bost, A., Chan, E., \& Lynch, R. (2006). Defining Liberal Arts Education. Unpublished manuscript.

Retrieved from http://www. liberalarts.wabash.edu/research-andpublications/

Botterill, C., \& Brown, M. (2002). Emotion and perspective in sport. International Journal of Sport Psychology, 33(1), 38-60.

Bouchet, A., \& Hutchinson, M. (2011).

Organizational escalation and retreat in university athletics: Brand insulation in Birmingham-Southern College's transition to Division III athletics. Journal of Intercollegiate Sport, 4(2), 261-282. doi: 1010007/s11136-0151214-1

Boyatzis, R.E., Stubbs, E.C., \& Taylor, S.N. (2002). Learning cognitive and emotional intelligence competencies through graduate management education. Academy of Management Learning and Education, 12), 150-162. doi: 10.5465/AMLE.2002.8509345

Brand, M. N. (2006). The role and value of intercollegiate athletics in universities. Journal of the
Philosophy of Sport, 33, 9-20. doi: 10.1080/00948705.2006.9714687

Caruso, D. (2004). Defining the inkblot called emotional intelligence. Issues in Emotional Intelligence, 1(1), 1-8.

Clark, S.C., Callister, R., \& Wallace, R. (2003). Undergraduate management skills courses and students' emotional intelligence. Journal of Management Education, 27(1), 3-23. doi: $10.1177 / 1052562902239246$

Cohen, J (1988). Statistical power analysis for the behavioral sciences (2nd ed.). Hillsdale, NJ: Erlbaum.

Côté, J., \& Gilbert, W. (2009). An integrative definition of coaching effectiveness and expertise. International Journal of Sports Science and Coaching, 4(3), 307-323. doi: 10.1260/174795409789623892 Crombie, D., Lombard, C., \& Noakes, T. (2009). Emotional intelligence scores predict team sports performance in a national cricket competition. International Journal of Sports Science and Coaching, 4(2), 209-224. doi: 10.1260/174795409788549544

Crombie, D., Lombard, C., \& Noakes, T. (2011). Increasing emotional intelligence in cricketers: An intervention study. International Journal of Sports Science and Coaching, 6(1), 69-86. doi: 10.1260/1747-9541.6.1.69

Danish, S.J. (1983). Musings about personal competence: The contributions of sport, health, and fitness. American Journal of Community Psychology, 11(3), 221-240. doi: 10.1007/BF00893365 
Danish, S.J., Petitpas, A.J., \& Hale, B.D. (2007): Sport as a context for developing competence. In Smith, D. \& Bar-Eli, M., (Eds.), Essential Readings in Sport and Exercise Psychology, (pp. 412422). Champaign, IL: Human Kinetics.

Durden, W. G., (2009). Frontier Pragmatism: The importance of place in an undergraduate education. Retrieved from http://www.dickinson.edu/news/ convocation/ 2009/remarks2009. html

Emerson, J., Brooks, R. L., \& McKenzie, E. C. (2009). College athletics and student achievement: The evidence at small colleges. New Directions for Institutional Research, 2009(144), 65-76. doi: 10.1002/ir.314

Feezell, R. (2015). Branding the role and value of intercollegiate athletics. Journal of the Philosophy of Sport, 42(2), 185-207. doi: 10.1080/00948705.2014.911098

Feezell, T. (2015). Educated ignorance:

What faculty don't know and why faculty can't lead intercollegiate athletics reform. Journal of Amateur Sport, 1(1), 81-100. doi: 10.17161/jas.v1i1.4925

Gilbert, W. D. \& Trudel, P. (2001). Learning to coach through experience: Reflection in model youth sport coaches. Journal of Teaching in Physical Education, 21, 16-34. doi: 10.1123/jtpe.21.1.16

Gould, D. \& Carson, S. (2008). Life skills development through sport: Current status and future directions. International Review of Sport and
Exercise Psychology, 1(1), 58-78. doi: 10.1080/17509840701834573 Hanin, Y.L. (2000). Emotions in Sport. Champlain, IL: Human Kinetics. Henson, R. K. (2001). Understanding internal consistency reliability estimates: A conceptual primer on coefficient alpha. Measurement and evaluation in counseling and development, 34(3), 177.

Houghton, J.D., Wu, J., Godwin, J.L., Neck, C.P., \& Manz, C.C. (2012). Effective stress management: A model of emotional intelligence, self-leadership, and student stress coping. Journal of Management Education, 36(2), 220238. doi: $10.1177 / 1052562911430205$ Jarvis, P. (1987). Adult learning in the social context. London: Croom Helm.

Joseph, D.L., \& Newman, D.A. (2010). Emotional intelligence: An integrative meta-analysis and cascading model. Journal of Applied Psychology, 95, 54-78. doi: 10.1037/a0017286

Knapp, J.C. (2013). For liberal arts colleges, no time to be content with status quo. Vital Speeches of the Day, 79(12), 397-400.

Kolb, D. A. (1984). Experiential learning: Experience as the source of learning and development. Englewood Cliff, NJ: Prentice Hall.

Lam, T. L. \& Kirby, S.L. (2002). Is emotional intelligence an advantage? An exploration of the impact of emotional and general intelligence on individual performance. The Journal of Social Psychology, 142(1), 133-143. doi: 10.1080/00224540209603891 
Lane, A. M., Thelwell, R. C., Lowther, J., \& Devonport, T. J. (2009). Emotional intelligence and psychological skills use among athletes. Social Behavior and Personality, 37(2), 195-201. doi: 10.2224/sbp.2009.37.2.195

Lillis, M. P. (2012). Faculty emotional intelligence and student-faculty interactions: Implications for student retention. Journal of College Student Retention, 13(2), 155-178. doi: 10.2190/ CS.13.2.b

Lomax, R. G., \& Hahs-Vaughn, D. L. (2012). An introduction to statistical concepts. Routledge.

Lowry, R.L. (2014). A traditional, liberal arts, competency-based education. Innovative Practices, Fall. Retrieved from https://www.acenet.edu/the-presidency/columns-and-features/Pages/A-Traditional,-Liberal-Arts,-Competency-BasedEducation.aspx

Lytle, J.H. (2003). Missions, markets, and muscle: The intersection of ideals and realities in the debate over athletics at selective liberal arts colleges (Doctoral dissertation). University of Pennsylvania. Retrieved from ProQuest. (3084867) Márquez, P. G. O., Martín, R. P., \& Brackett, M. A. (2006). Relating emotional intelligence to social competence and academic achievement in high school students. Psicothema, 18(Suplemento), 118-123.

Mayer, J.D., Salovey, P., \& Caruso, D.R., (2000): Models of emotional intelligence. In Sternberg, R. J., (Ed.), Handbook of Intelligence, (pp. 396-420).
New York, NY: Cambridge University Press.

Mayer, J.D., Salovey, P., Caruso, D.R., \& Cherkasskiy, L. (2011): Emotional intelligence. In Sternberg, R.J. \& Kaufman, S.B., The Cambridge Handbook of Intelligence, (pp. 528-545). New York, NY: Cambridge University Press.

Meyer, B. B., \& Fletcher, T. B. (2007). Emotional intelligence: A theoretical overview and implications for research and professional practice in sport psychology. Journal of $A p$ plied Sport Psychology, 19(1), 1-15. doi: 10.1080/10413200601102904

Mikolajczak, M. (2009). Going beyond the ability-trait debate: The three-level model of emotional intelligence, Electric Journal of Applied Psychology, 5(2), 25-31.

Mills, L. B. (2009). A meta-analysis of the relationship between emotional intelligence and effective leadership. Journal of Curriculum and Instruction, 3(2), 22-38. doi:10.3776/joci.2009. v3n2p22-38

National Collegiate Athletic Association. (2015). NCAA Division III intercollegiate athletics programs report (2004-2014). Indianapolis, IN: Daniel L. Fulks. National Liberal Arts College Rankings. (2016). US News and World Report. Retrieved from http://colleges. usnews.rankingsandreviews.com/ best-colleges/rankings/national-liberal-arts-colleges

Nelis, D., Kotsou, I., Quoidbach, J., Hansenne, M., Weyens, F., Dupuis, 
P., \& Mikolajczak, M. (2011). Increasing emotional competence improves psychological and physical well-being, social relationships and employability. Emotion, 11(2), 354-366. doi: 10.1037/ a0021554

O’Boyle, E.H., Humphrey, R.H., Pollack, J.M., Hawver, T.H., \& Story, P.A. (2011). The relation between emotional intelligence and job performance: A meta-analysis. Journal of Organizational Behavior, 32, 788-818. doi: 10.1002/job.714

Perlini, A. H., \& Halverson, T. R. (2006). Emotional intelligence in the National Hockey League. Canadian Journal of Behavioural Science, 38(2), 109-119. doi: 10.1037/cjbs2006001

Petrides, K.V., Frederickson, N., \& Furnham, A. (2004). The role of trait emotional intelligence in academic performance and deviant behavior at school. Personality and Individual Differences, 36, 277-293. doi: 10.1016/ S0191-8869(03)00084-9

Petrides, K.V. \& Furnham, A. (2000). On the dimensional structure of emotional intelligence. Personality and Individual Differences, 29, 313-320. doi: 10.1016/S0191-8869(99)00195-6

Pool, L. D. \& Qualter, P. (2013). Emotional self-efficacy, graduate employability, and career satisfactions: Testing the associations. Australian Journal of Psychology, 65, 214-223. doi: 10.1111/ajpy.12023

Qualter, P., Whiteley, H., Morley, A., \& Dudiak, H. (2009). The role of emotional Intelligence in the deci- sion to persist with academic studies in HE. Research in Post-Compulsory Education, 14(3), 219-231. doi: 10.1080/13596740903139255

Rasmussen, R. \& Rasmussen, W. (2003). NCAA Division III profile of institutions and conferences. National Association of Division III Atbletic Administrators Resource Library. Retrieved from http://www.uaa.rochester.edu/ Administrative/Form_and_Document_Library/Division_III_Profile. pdf

Salovey, P. \& Mayer, J.D. (1990). Emotional intelligence. Imagination, Cognition, and Personality, 9, 185-211. doi: 10.2190/DUGG-P24E-52WK6CDG

Sauer, S., Desmond, S., \& Heintzelman, M. (2013). Beyond the playing field: The role of athletic participation in early career success. Personnel Review, 42(6), 644-661. doi: 10.1108/PR-082012-0149

Schutte, N.S. (2014). Social environment contexts of trait emotional intelligence. Journal of Human Behavior in the Social Environment, 24, 741-750. doi: 10.1080/10911359.2013.866065 Schutte, N. S., \& Malouff, J. M. (2002). Incorporating emotional skills content in a college transition course enhances student retention. Journal of 1st-Year Experience, 14(1), 7-21.

Schutte, N. S., \& Malouff, J. M. (2013). Adaptive emotional functioning: A comprehensive model of emotional intelligence. In C. Mohiyeddini, M. Eysenck, \& S. Bauer (Eds), Handbook 
of Psychology of Emotions: Recent Theoretical Perspectives and Novel Empirical Findings (pp. 469-488). Hauppauge, NY: Nova Science Publishers.

Schutte, N. S., Malouff, J. M., \& Bhullar, N. (2009): The assessing emotions scale. In Stough, C., Saklofske, D., \& Parker, J. (Eds.) Assessing emotional intelligence, (pp. 119-135). New York, NY: Springer Publishing.

Schutte, N. S., Malouff, J. M., Bobik, C., Coston, T. D., Greeson, C., Jedlicka, C., ... \& Wendorf, G. (2001). Emotional intelligence and interpersonal relations. The Journal of Social Psychology, 141(4), 523-536. doi: 10.1080/00224540109600569

Schutte, N. S., Malouff, J. M., Hall, L.E., Haggerty, D.J., Cooper, J.T., Golden, C.J., \& Dornheim, L. (1998). Development and validation of a measure of emotional intelligence. Personality and Individual Differences, 25, 167-177. doi: 10.1016/S0191-8869(98)00001-4

Schutte, N. S., Malouff, J. M., \& Hine, D. W. (2011). The association of ability and trait emotional intelligence with alcohol problems. Addiction Research and Theory, 19, 260-265. doi: 10.3109/16066359.2010.512108

Schutte, N. S., Malouff, J. M., Thorsteinsson, E. B., Bhullar, N., \& Rooke, S. E. (2007). A meta-analytic investigation of the relationship between emotional intelligence and health. Personality and Individual Differences, 42, 921-933. doi: 10.1016/j.paid.2006.09.003

Seifert, T.A., Goodman, K.M., Lindsay, N., Jorgensen, J.D., Wolniak, G. C.,
Pascarella, E.T., \& Blaich, C. (2008). The effects of liberal arts experiences on liberal arts outcomes. Research in Higher Education, 49(2), 107-125. doi: 10.1007/s11162-007-9070-7

Shulman, J. L. \& Bowen, W. G. (2001). The game of life: College sports and educational values. Princeton University Press.

Song, L.J., Huang, G., Peng, K.Z., Law, K.S., Wong, C., \& Chen, Z. (2010). The differential effects of general mental ability and emotional intelligence on academic performance and social interactions. Intelligence, 38, 137 148. doi: $10.1016 /$ j.intell.2009.09.003 Sough, C., Clements, M., Wallish, L., \& Downey, L. (2009): Emotional intelligence in sport: Theoretical linkages and preliminary empirical relationships from basketball. In Stough, C., Saklofske, D. H., \& Parker, J. D. (Eds.), Assessing Emotional Intelligence: Theory, Research, and Applications, (pp. 291-305). Springer Science Media. Stancill, J. (2014, October 31). UNC$\mathrm{CH}$ faculty want to regain trust, take stronger stance on athletics. Newsobserver.com, Retrieved form http:/ /www.newsobserver.com /2014/10/31/4281923_unc-chfaculty-want-to-regain.html?sp= / 99/102/110/112/973/\&rh=1 Stough, C., Saklofske, D., \& Parker, J. (2009): A brief analysis of 20 years of emotional intelligence: An introduction to assessing emotional intelligence: Theory, research, and applications. In Stough, C., Saklofske, D., 
\& Parker, J. (Eds.) Assessing emotional intelligence, (pp. 119-135). New York, NY: Springer Publishing.

Tabachnick, B.G. \& Fidell, C.S. (2013). Using multivariate statists ( $6^{\text {th }}$ ed.). Pearson.

Thelwell, R. C., Lane, A. M., Weston, N. J., \& Greenlees, I. A. (2008). Examining relationships between emotional intelligence and coaching efficacy. International Journal of Sport and Exercise Psychology, 6(2), 224-235. doi: 10.1080/1612197X.2008.9671863

Van Rooy, D.L. \& Viswesvaran, C. (2007): Assessing emotional intelligence in adults: A review of the most popular measures. In Bar-On, R., Maree, J.G., \& Elias, M.J., Educating People to be emotionally intelligent, (pp. 259-272). Westport, CT: Praeger Publishers. Vela, R. H. (2007). Emotional intelligence: An education-based approach to improve student achievement.
National Forum of Applied Educational Research Journal, 20(1), 80-94. Vella, S. A., Crowe, T. P., \& Oades, L. G. (2013). Increasing the effectiveness of formal coach education: Evidence of a parallel process. International Journal of Sports Science and Coaching, 8(2), 417430. doi: 10.1007/s11136-015-1214-1

Whitney, C. (2010). Social Supports among college students and measures of alcohol use, perceived stress, satisfaction with life, emotional intelligence and coping. Journal of Student Wellbeing, 4(1), 49-67. doi: 10.21913/ JSW.v4i1.588

Zizzi, S., Deaner, H., \& Hirschhorn, D. (2003). The relationship between emotional intelligence and performance among college basketball players. Journal of Applied Sport Psychology, 15(3), 262-269. doi: 10.1080/10413200305390 